\title{
Experience with synchronous and asynchronous tools in online teaching: Application to Thermal Renewable Energies of the Degree in Energy Engineering at UPV due to the pandemic produced by COVID-19
}

\begin{abstract}
Carlos Varga-Salgado ${ }^{a}$, Paula Bastida-Molina ${ }^{b}$, Manuel Alcazar-Ortega ${ }^{c}$ y Lina Montuori $^{\text {d }}$

${ }^{a}$ Departamento de Ingeniería Eléctrica, Universitat Politècnica de València, Camino de Vera, s/n, edificio 5E, planta baja.46022 Valencia (España), carvarsa@upvnet.upv.es, ${ }^{\mathrm{b}}$ Instituto de Ingeniería Energética, Universitat Politècnica de València, Camino de Vera, s/n, edificio 8E, acceso $\mathrm{F}, 2^{\mathrm{a}}$ planta. 46022 Valencia (España), paubasmo@etsid.upv.es, c Departamento de Ingeniería Eléctrica, Universitat Politècnica de València, Camino de Vera, s/n, edificio 5E, $2^{\mathrm{a}}$ planta. 46022 Valencia (España), malcazar@iiie.upv.es, ${ }^{\mathrm{d}}$ Departamento de Termodinámica Aplicada, Universitat Politècnica de València, Camino de Vera, $\mathrm{s} / \mathrm{n}$, edificio 5J, $2^{\mathrm{a}}$ planta. 46022 Valencia (España), lmontuori@upvnet.upv.es
\end{abstract}

\begin{abstract}
Due to the pandemic provoked by COVID-19 in March 2020, the Polytechnic University of Valencia (UPV), following the Government's guidelines, changed the modality of the formal lectures from face-to-face to online teaching. Professors and students had the challenge of adapting to the new model to continue the semester. In this paper, the results of applying online teaching using both: synchronous and asynchronous lectures and the comparison with the traditional course are shown. The synchronous tools used is MS Teams. Among the asynchronous tools used to create the screencast videos are PoliformaT (Own tool designed by UPV) and MS Powerpoint. The platforms used to upload and public the produced videos are media UPV and MS Stream. Also, PoliformaT was used to perform exams and task and to communicate with students, submit works, take exams and access to the information shared by professors. As a result, it can be highlighted that, although the effort to mount the subject the first year, the learning task is facilitated for the student and the professor can amortize the work in the following years, additionally the average mark was higher applying the online method.
\end{abstract}

Keywords: Online teaching, asynchronous teaching tool, synchronous teaching tool. 


\section{Introduction}

Due to the state of alarm produced in Spain in March 2020, provoked by the expansion of the pandemic caused by the COVID-19 disease, the entire country practically paralyzes, allowing only the operation of essential services to cover the basics needs of the whole country. Due to the prohibition of face-to-face meetings and since teaching is not an essential service in times of emergency, educational institutions stopped their classroom academic activities on March 15, 2020. According to an agreement with other universities and the Ministry of Education of the Generalitat Valenciana, culture and sport of the Valencian Community, it is decided to continue the university activity through online courses.

Synchronous and asynchronous tools are not new tools, but such terminology has become known and spread in the teaching field, due to the pandemic. Synchronous tools are those virtual tools that allow direct interaction and in real time between professors and students. Asynchronous teaching tools allow class material to be available to students so that can be consulted at any time. The material could include videos, books, presentations, etc.

In this paper, the results of the online methodology applied to a traditional face-to-face course are shown. The subject chosen to apply the method is Thermal Renewable Energies of the Energy engineering Degree at the Polytechnic University of Valencia. The use of this methodology has particular interest due to the crises caused by the SARS-CoV-2 virus and the change of classroom classes to non-classroom classes. The method applied in both: synchronous and asynchronous lectures.

\section{Methodology}

In this methodology, both kinds of lectures have been tested: synchronous and asynchronous. The method for the synchronous lectures is shown in figure 1. The method for the asynchronous lectures is shown in figure 2. 
This loop repeats from the first to the last synchronous session.

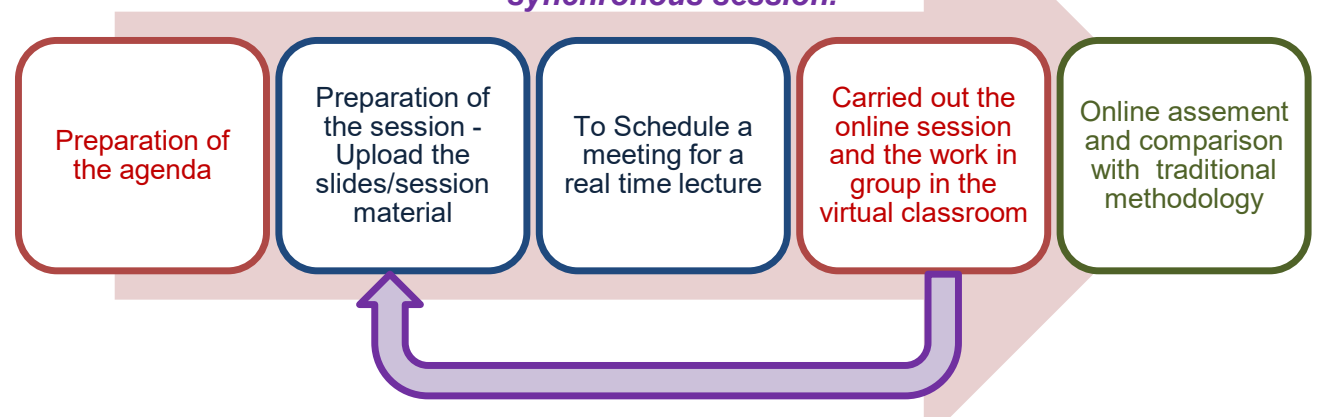

Fig. 1 Methodology for the synchronous lectures

Source: Argente, E., Garcia-Fornes, A. \& Espinosa, A. (2005); ASIC - UPV (2020); Peña, B., Zabalza, I., Llera, E., Usón, S. (2019)

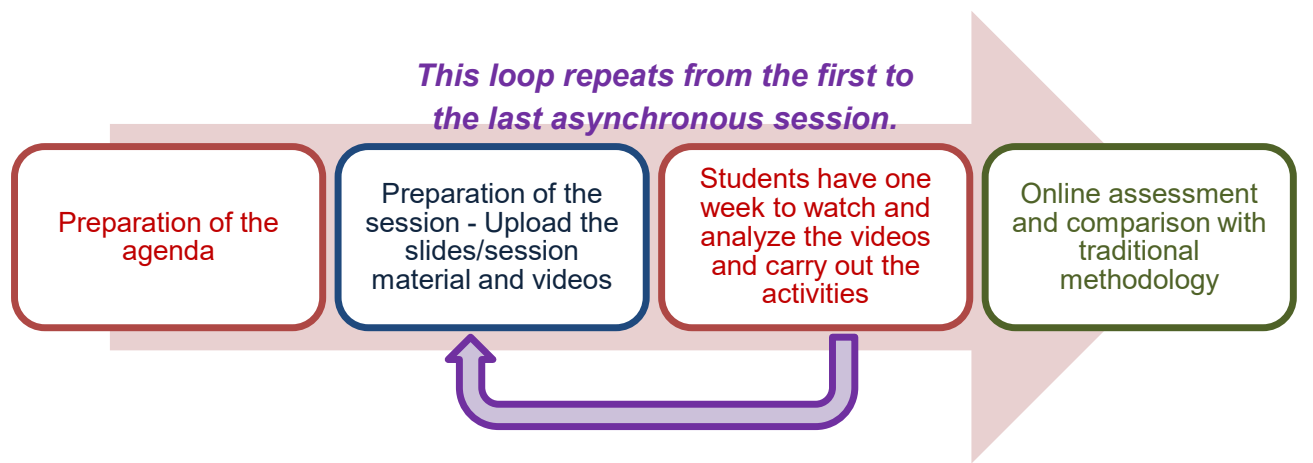

Fig. 2 Methodology for the asynchronous lectures.

Source: Argente, E., Garcia-Fornes, A. \& Espinosa, A. (2005); ASIC - UPV (2020); Peña, B., Zabalza, I., Llera, E., Usón, S. (2019)

\section{Assessment}

The assessment method has been applied as usual classroom lectures as much as possible. In the in-person evaluation, the exam consists of three parts: 1 multiple-choice-test (10 questions), two practical problems and a question to develop by the student. The exam is carried out through the traditional method in a classroom. The online exam is performed employing the Exam tool, available in PoliformaT. The test and the problems were 
previously designed. In the case of the practical problems, the students had to send the numerical results, and additionally, they must upload a picture of the solution problem (Table 1). The exam time had a reduction of $30 \%$.

Table 1: comparison between the online and conventional evaluation.

\begin{tabular}{|l|c|c|c|}
\hline \multicolumn{1}{c}{ Exam } & Traditional (2019) & Online (2020) & $\begin{array}{c}\text { Time } \\
\text { reduction }\end{array}$ \\
\hline Multiple choice test & 10 questions, 15 minutes & 10 questions, 7 minutes & $53 \%$ \\
\hline Practical problem 1 & $40 \mathrm{~min}$ & $25 \mathrm{~min}$ & $37.5 \%$ \\
\hline Practical problem 2 & $35 \mathrm{~min}$ & $25 \mathrm{~min}$ & $31.5 \%$ \\
\hline Practical problem 3 & - & $20 \mathrm{~min}$ & \\
\hline Questions & 1 question $(20 \mathrm{~min})$ & - & \\
\hline Total & $110 \mathrm{~min}$ & $77 \mathrm{~min}$ & $30 \%$ \\
\hline
\end{tabular}

\section{Used tools}

The tools used are open-source software, UPV developing tools or UPV has the license.

\subsection{Synchronous teaching tools}

Synchronous tools allow direct interaction in real time between professor and students. Using these tools, it is possible to keep the usual lecture schedule. The synchronous tool used in this method is MS Teams (Figure 3), it is a payment tool developed by Microsoft. It is integrated into the office 365 package. MS Teams allow virtual meetings, chats, file sharing and screen sharing. The UPV has the license for the whole university community. Although MS Teams is used in this method for virtual online teaching synchronously; it can also be used for asynchronous teaching and tutoring. Some advantages of this tool are the high number of simultaneous users (500 connections at the same time), it allows the professor to mute the rest of the participants with a click and also any member of the meeting could take control of the class or share the screen. This option can be blocked or personalized by the professor. It has other properties such as recording; therefore, the students can watch the videos later to review the lectures (Chiñas-Palacios, C., VargasSalgado, C., Águila-Leon, J. \& Garcia E. 2019). 


\subsection{Asynchronous teaching tools}

Asynchronous teaching tools allow lectures to be available for students at any time. The material could include videos, books, slides, etc. The tools used are UPV's asynchronous tools, open-source external tools and external tools of which the UPV has the license. The asynchronous tools used in this methodology are explained below:

\subsubsection{Tools to share documents and send information to students - PoliformaT}

The UPV asynchronous platform is PoliformaT. Both professor and students are familiar with its use. PoliformaT is used to share documents, send messages to students, take tests, etc. Also integrated into PoliformaT, it can be found the Lessons tool, which is used to create and access to contents visually and intuitively (Gomez-Tejedor, J., Molina Mateo, J., Serrano, M.A., Meseguer Dueñas, J., Vidaurre, A. \& Riera, J. 2019). Figure 4 shows a picture of the PoliformaT platform.

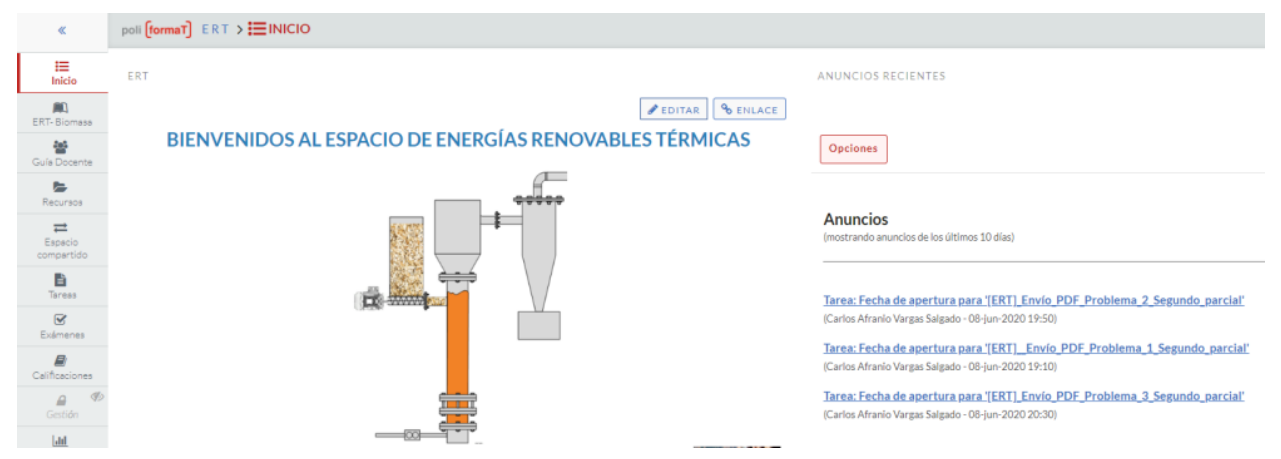

\subsubsection{Screencast tools}

Fig. 4. PoliformaT platform

To make videos was used PowerPoint, which is a payment tool integrated into the office 365 package. It is the most widely used tool for making presentations at UPV. There are two ways to screen record: Using the record slide option, to record the audio in every slide (Figure 5) and using the screen recording option to record the screen.
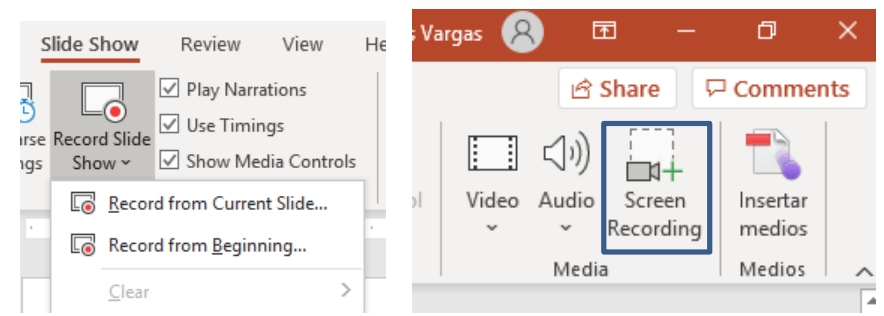

Fig. 5. Recording (Up) and Screen recording (down) in PowerPoint 


\subsubsection{Tools to share videos}

Two options are used to disseminate the videos: UPV media and Microsoft Stream. Media UPV is an own UPV application to share videos; the videos can be hidden in such a way that to watch the video a link is required. To upload a video, it is needed to be part of the university community. Videos can be embedded in Lessons, and the link can also be shared with students. Figure 6 shows the media UPV screen. Another tool used to share videos is Microsoft Stream. When a synchronous lecture is recorded in Teams, the video is stored in the Microsoft Stream database (Figure 7).

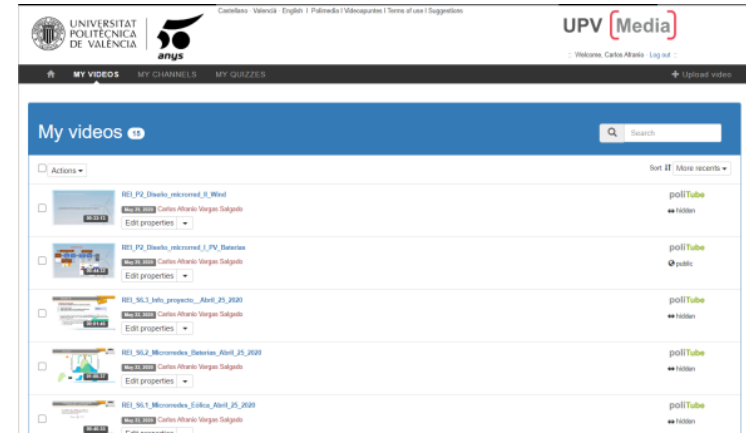

Fig. 6. media UPV

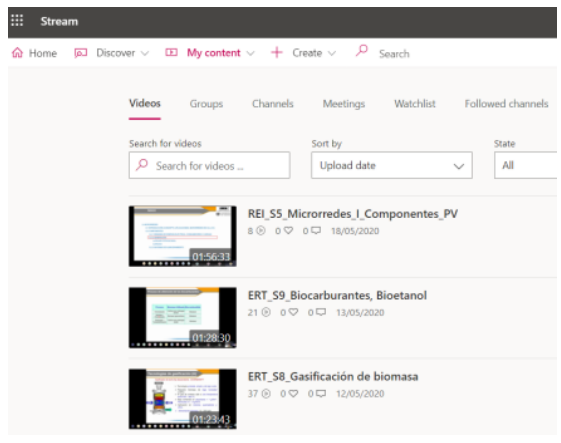

Fig. 7. Microsoft Screen

\section{Results}

\subsection{Results of the methodology}

The results of the method are shown in this section. The agenda of the course is shown in figure 8 . The contents of the subject are shown in figure 9. The link to access the PDF with the explanation of practice 3 is shown in figure 10 . When a new meeting is scheduled, it is added to the student's calendar (Figure 11). Once the online session has finished, the video is upload to media UPV or Microsoft Stream (Figure 12) 


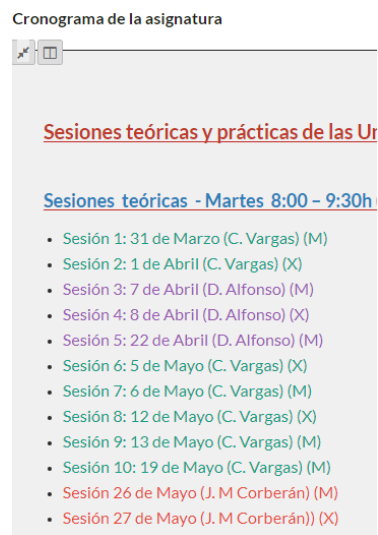

Fig. 8 Agenda of the course

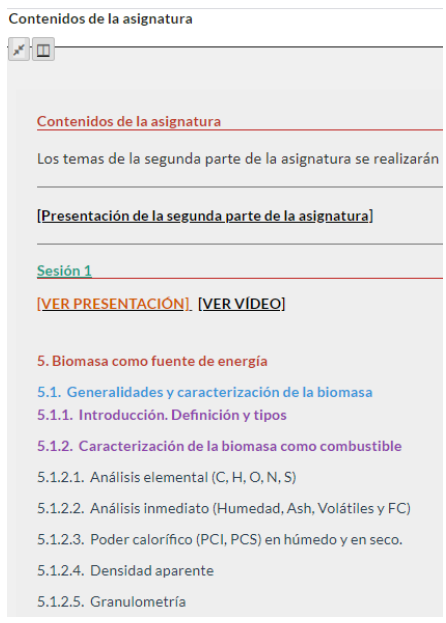

Fig. 9. Subject content included in the preparation sessions.

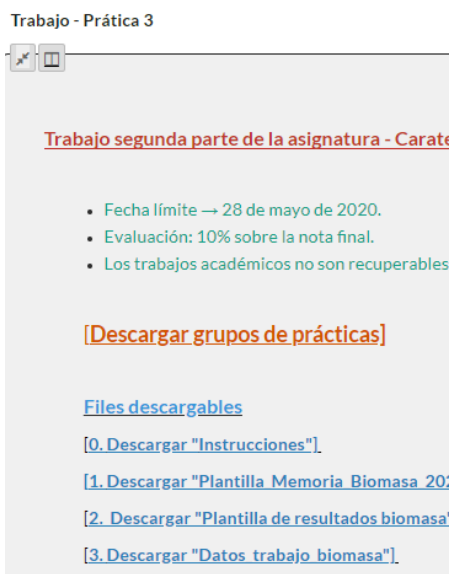

Fig. 10. Link to access the information of practice 3 .

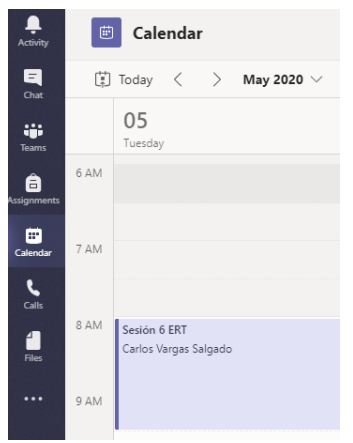

Fig. 11. Scheduling a meeting for a real time lecture

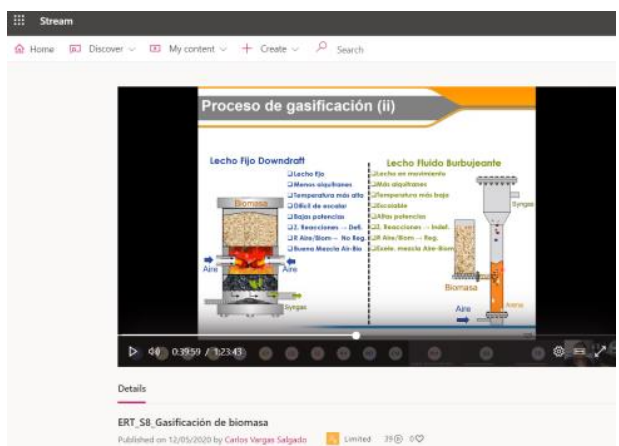

Fig. 12. Video of an asynchronous lecture.

\subsection{Assesment}

The online evaluation is carried out through a test and three practical problems. An example of the test is shown in figure 13 and part of a problem is shown in figure 14.

$$
\begin{aligned}
& \text { Cuál de las siguientes ecuaciones corresponde a un proceso de combustión de biomasa: } \\
& \text { A. } \mathrm{CH}_{1,44} \mathrm{O}_{0,66}+w\left(\mathrm{H}_{2} \mathrm{O}\right)+1,03\left(\mathrm{O}_{2}+3,76 \mathrm{~N}_{2}\right) \rightarrow \mathrm{CO}_{2}+(0,72+w) \mathrm{H}_{2} \mathrm{O}+3,87 \mathrm{~N}_{2} \\
& \text { × B. } \mathrm{CH}_{1,44} \mathrm{O}_{0,66}+\mathrm{H}_{2} \mathrm{O}+m\left(\mathrm{O}_{2}+3,76 \mathrm{~N}_{2}\right) \rightarrow x_{1} \mathrm{H}_{2}+x_{2} \mathrm{CO}+x_{3} \mathrm{CO}_{2}+x_{4} \mathrm{H}_{2} \mathrm{O}+x_{5} \mathrm{CH}_{4}+3,76 \mathrm{mN}_{2} \\
& \text { c. } \mathrm{C}_{n} \mathrm{H}_{m} \mathrm{O}_{p} \text { (Biomasa) } \stackrel{\text { Calor }}{\longrightarrow} \mathrm{C}(\text { Char })+\sum_{\text {Li. }} \mathrm{C}_{x} \mathrm{H}_{y} \mathrm{O}_{z}+\sum_{\text {Gas }} \mathrm{C}_{a} \mathrm{H}_{b} \mathrm{O}_{c}+\mathrm{H}_{2} \mathrm{O}
\end{aligned}
$$

Fig. 13. Test question example. 
Experience with synchronous and asynchronous tools in online teaching: Application to Thermal Renewable Energies of the Degree in Energy Engineering at UPV due to the pandemic produced by COVID-19

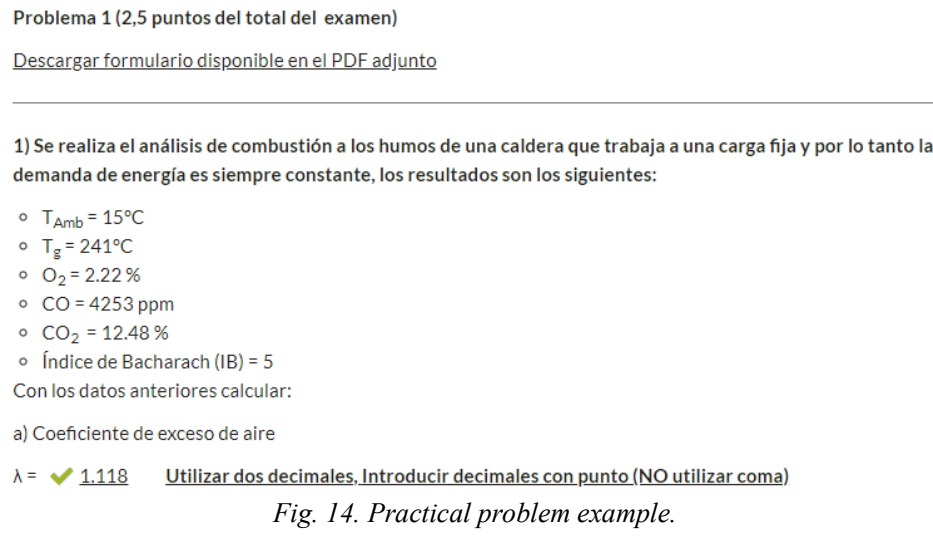

Fig. 14. Practical problem example.

\subsection{Traditional and online sessions - comparison the evaluation results}

Table 2 shows the comparison of the 2019 and 2020 assessment results (Traditional and online evaluation method). As a result, the average mark increase from 5.9 (traditional evaluation) to 7.3 (Online evaluation). To avoid the students had time to read the notes, the time for developing the exam was reduced by $30 \%$ respect to the classroom exam.

Figure 15 shows (from highest to lowest), the marks of all 55 students of the traditional course and the 53 students of the online course. It can be noticed that in the online evaluation, the marks are bigger.

Table 2. Average, maximum, and minimum mark. Traditional evaluation method vs Online method

\begin{tabular}{|c|c|c|}
\hline Mark & $\mathbf{2 0 1 9}$ & $\mathbf{2 0 2 0}$ \\
\hline Average & 5.9 & 7.3 \\
\hline Maximum & 9.9 & 9.8 \\
\hline Minimum & 1.5 & 2.7 \\
\hline
\end{tabular}

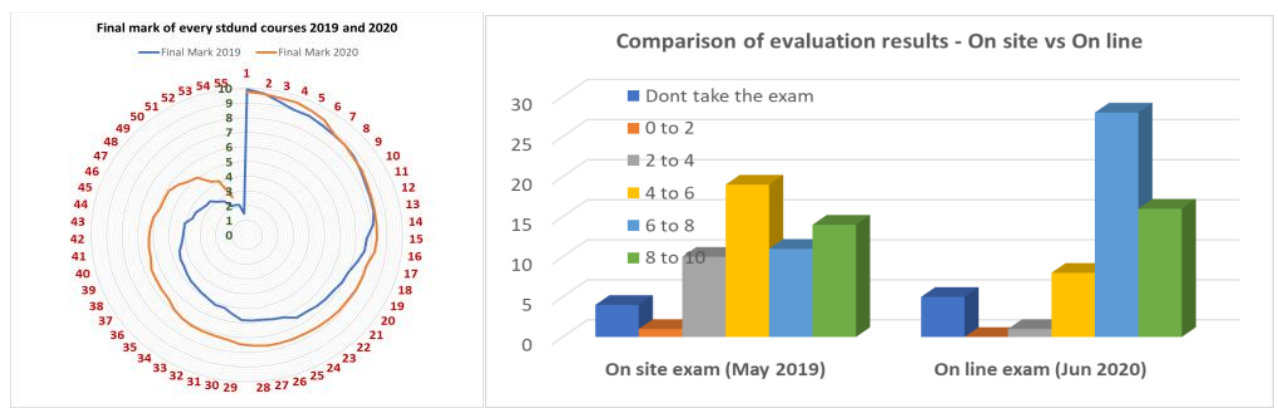

Fig. 15. Comparison of the evaluation results. 


\section{Conclusions}

Currently, multiple tools allow online teaching. Since there is not one single tool which integrates all in one, multiple applications must be used. If it has never been used some of these applications, it could take effort and time to choose them and learn how to use them. This paper presents the experience of using various tools that allow both synchronous and asynchronous teaching, saving time in the selection of these tools. These tools were applied to teach online in the Thermal Renewable Energy Course, due to the state of alarm provoked by the pandemic of COVID-19.

It can be concluded, not only from the results of this paper but according to the UPV experience that it is possible to carry out online teaching. Maybe the main problem is the evaluation. The results of the evaluation of the 2019 course have been compared with the results of the 2020 course. Although the time given to students to resolve the test and the problems were reduced to avoid reading the class material and the difficulty of the exam was similar, the average mark increases from 5.9 to 7.3 . It was not possible to control if the student was reading the slides, probably the higher average mark is related to the possibility of reading the class material.

In future work must evaluation methods to guarantee equality for all the students must be analyzed.

\section{Acknowledgements}

This work was supported in part by the regional public administration of Valencia under the grant ACIF/2018/106

\section{References}

Argente, E., Garcia-Fornes, A., Espinosa, A. (2016) “Aplicando la metodología Flipped-Teaching en el Grado de Ingeniería Informática: una experiencia práctica” XXII Jenui. Almería.

ASIC - UPV (2020) "Guía de utilización de la Plantilla para la inserción de Unidades Didácticas para Microsoft Word 2010, 2013, $2015 \quad$ y $\quad$ O365” http://www.upv.es/entidades/ASIC/catalogo/U0838895.pdf

Chiñas-Palacios, C., Vargas-Salgado, C., Águila-Leon, J., Garcia E. (2019) “Zoom y Moodle: acortando distancias entre universidades. Una experiencia entre la Universidad de Guadalajara, México y la Universidad Libre de Colombia” IN-RED 2019.

ETSII - UPV (2020) https://docenciaonline.blogs.upv.es/ 
Experience with synchronous and asynchronous tools in online teaching: Application to Thermal Renewable Energies of the Degree in Energy Engineering at UPV due to the pandemic produced by COVID-19

Gomez-Tejedor, J., Molina Mateo, J., Serrano, M.A., Meseguer Dueñas, J., Vidaurre, A., Riera, J. (2019) "Utilización de Lessons como herramienta de apoyo a la docencia inversa en la asignatura de Biofísica” IN-RED 2019.

Peña, B., Zabalza, I., Llera, E., Usón, S. (2019) "El modelo de aula inversa en el área de Máquinas y Motores Térmicos: análisis y comparación de experiencias” IN-RED 2019.

Sánchez Caballero, S. Montava-Jorda, M.A. Selles, A.V. Martínez. (2019) "Implementación de las tareas semanales mediante la plataforma PoliformaT para la mejora de resultados en el aprendizaje por proyectos" IN-RED 2019.

VI Jornada de Docencia Inversa en el Campus de Vera (2020) https://docenciainversa.blogs.upv.es/vijornada-de-docencia-inversa-en-el-campus-de-vera/ 